(Aus dem physiol. Institut der Columbia-Universität, College of Physicians and Surgeons, New York.)

\title{
Der Einfluss des intraabdominalen Druckes auf die Strömung in den Venen.
}

Von

\section{R. Burton-Dpitz.}

(Mit 2 Textfiguren.)

An der Vena jugularis externa ausgeführte Versuche ${ }^{\mathfrak{1}}$ ) ergaben die Tatsache, dass das Strömungsvolum während der Einatmung zunimmt, und dass die Zunahme ein direktes Verhältnis zu der Tiefe der Atembewegung bewahrt. Demgemäss traf es auch zu, dass die durch Reizung der Nervi phrenici verursachte Erniedrigung des Druckes in der Brusthöhle eine entsprechende Erhöhung des Blutvolums in der genannten Vene nach sich zog.

Entgegen diesem Resultate bedingte die Kontraktion des Zwerchfelles meistenteils eine Verlangsamung der Strömung in der Vene der hinteren Extremität, und zwar trat diese Hemmung zuweilen auch auf, wenn die Reizung der Nerven mit Strömen von nur geringer Stärke vorgenommen wurde. Gemäss diesem Befunde wurde angenommen, dass die Kontraktion des Zwerchfelles eine Erhöhung des Druckes in der Bauchböble und infolgedessen eine venöse Stauung in dem Gebiete der Cruralis nach sich zieht.

Um nun den Einfluss des intraabdominalen Druckes auf den Rücklauf des Blutes etwas näher zu bestimmen, wurden eine Reihe von Strommessungen an der Cruralis unter Obwaltung eines verschiedlichen Druckes in der Bauchhöhle vorgenommen. Die Versuche wurden während der Morphin-Äther-Narkose an mittelgrossen Hunden mittels der in der vorhergehenden Arbeit beschriebenen Stromuhr ausgeführt. Während diese das Stromvolum der Vene auf-

1) R. Burton-Opitz, Amer. Journ. of Physiol. Bd. 7 S. 435-459. 1902. 
zeichnete, wurde der intraabdominale Druck auf zweierlei Weise verschiedengradig erhöht. Es wurde entweder die vordere Bauchdecke mit den flachausgestreckten Händen stark nach hinten gedrückt, oder auch die Bauchhöhle mit Luft aufgebläht.

Folgende Anordnung wurde getroffen. Eine spitze Kanüle, welche mit einer Druckflasche in Verbindung stand, wurde seitlich in die Bauchhöhle eingeführt. Ein T-Rohr wurde eingeschaltet, um den in dieser obwaltenden Druck auf einen Quecksilbermanometer übertragen zu können. Der Venendruck wurde zentral von der Stromuhr mittels eines Gummimanometers gemessen.

Die Versuche ergaben sämtlich übereinstimmende Resultate, so dass die beistehende Kurve $^{1}$ ) als ein Beispiel aller dienen kann. Die Linie $A$ bis $D$ gibt im Vereine mit den von dem Chronometer aufgezeichneten Sekunden die in einer gewissen Zeit durch die Vena cruralis strömende Blutmenge $V F$ an. Unterhalb dieser Kurve ist der Venendruck $V D$ mit der Abseissa verzeichnet und oberhalb derselben der intraabdominale Druck $A D$. In diesem Falle wurde letzterer mittels eines umgekehrten, stark gedämpften Gummimanometers aufgeschrieben. Eine Erhöhung des Druckes verursachte somit eine Senkung dieses Schreibehebels. Die Sekundenlinie dient hier als Abeissa.

Die in einer Sekunde durch die Vene strömende Blutmenge betrug in diesem Falle im Mittel $0,89 \mathrm{ccm}(A-B)$. Zu gleicher Zeit wurde ein Venendruck von $6,1 \mathrm{~mm} \mathrm{Hg}$ und ein intraabdominaler Druck von $0,5 \mathrm{~mm} \mathrm{Hg}$ verzeichnet. Bei $B$ wurde letzterer langsam durch Einführung von Luft auf $70 \mathrm{~mm} \mathrm{Hg}$ erhöht. Gleichzeitig mit der Aufblähung der Bauchhöhle stieg der Venendruck auf $64 \mathrm{~mm}$ $\mathrm{Hg}$ an, während die Strommenge auf nahe Null erniedrigt wurde: $0,06 \mathrm{cem}$ pro Sekunde. Sobald der intraabdominale Druck durch Entfernung der Luft wieder erniedrigt wurde $(C)$, kehrten auch der Venendruck und das Strömungsvolum bald wieder auf normal zurück $(C-D)$.

Die verschiedenen Versuche sind unter Angabe aller Einzelheiten in der Tabelle (S. 160) zusammengefasst.

Die mit den Händen in der oben angegebenen Weise verursachte Erhöhung des Druckes führte immer eine weit schnellere venöse Stauung herbei, wahrscheinlich weil unter diesen Umständen

1) Die Kurve ist in zwei Teile geteilt. 
R. Burton-Opitz:

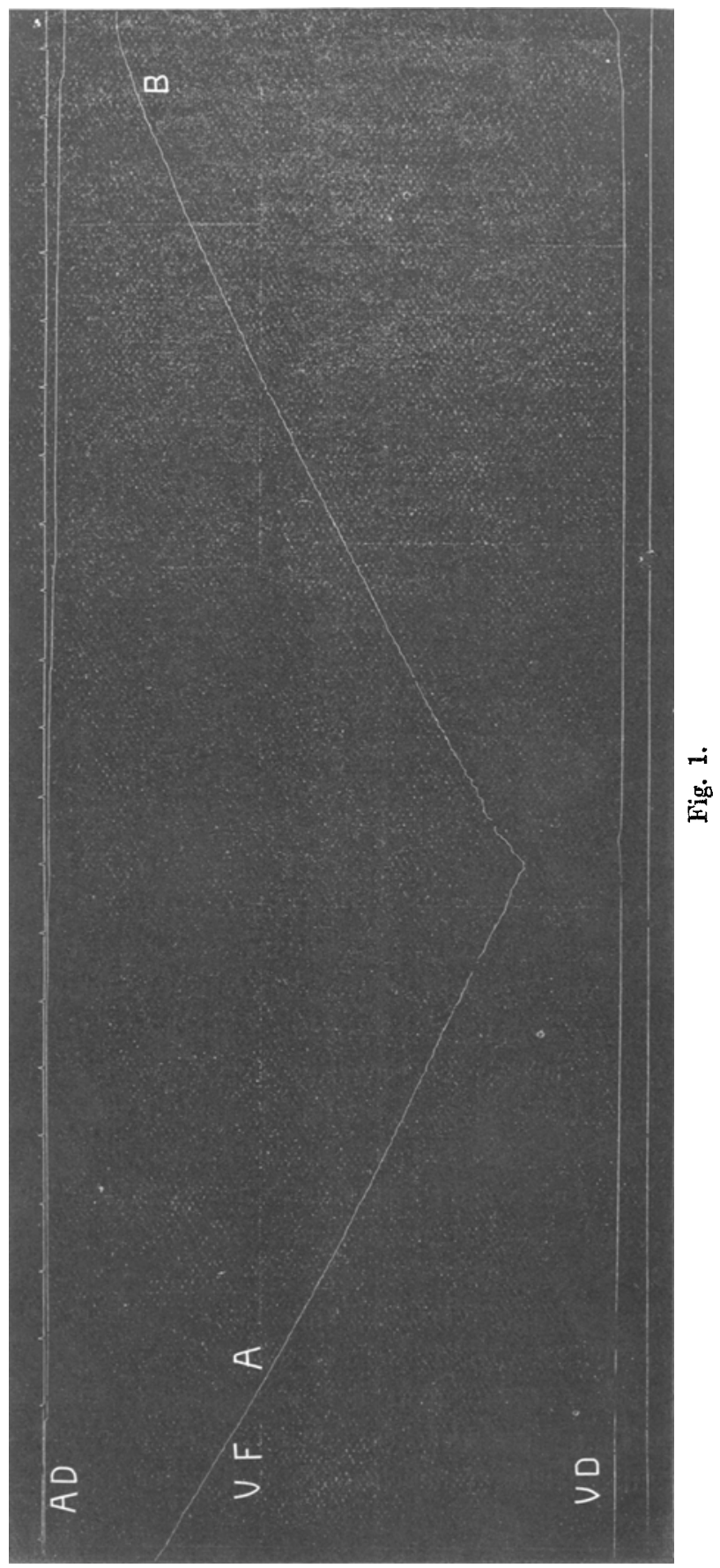


Der Einfluss des intraabdom. Druckes auf die Strömung in den Venen. 159

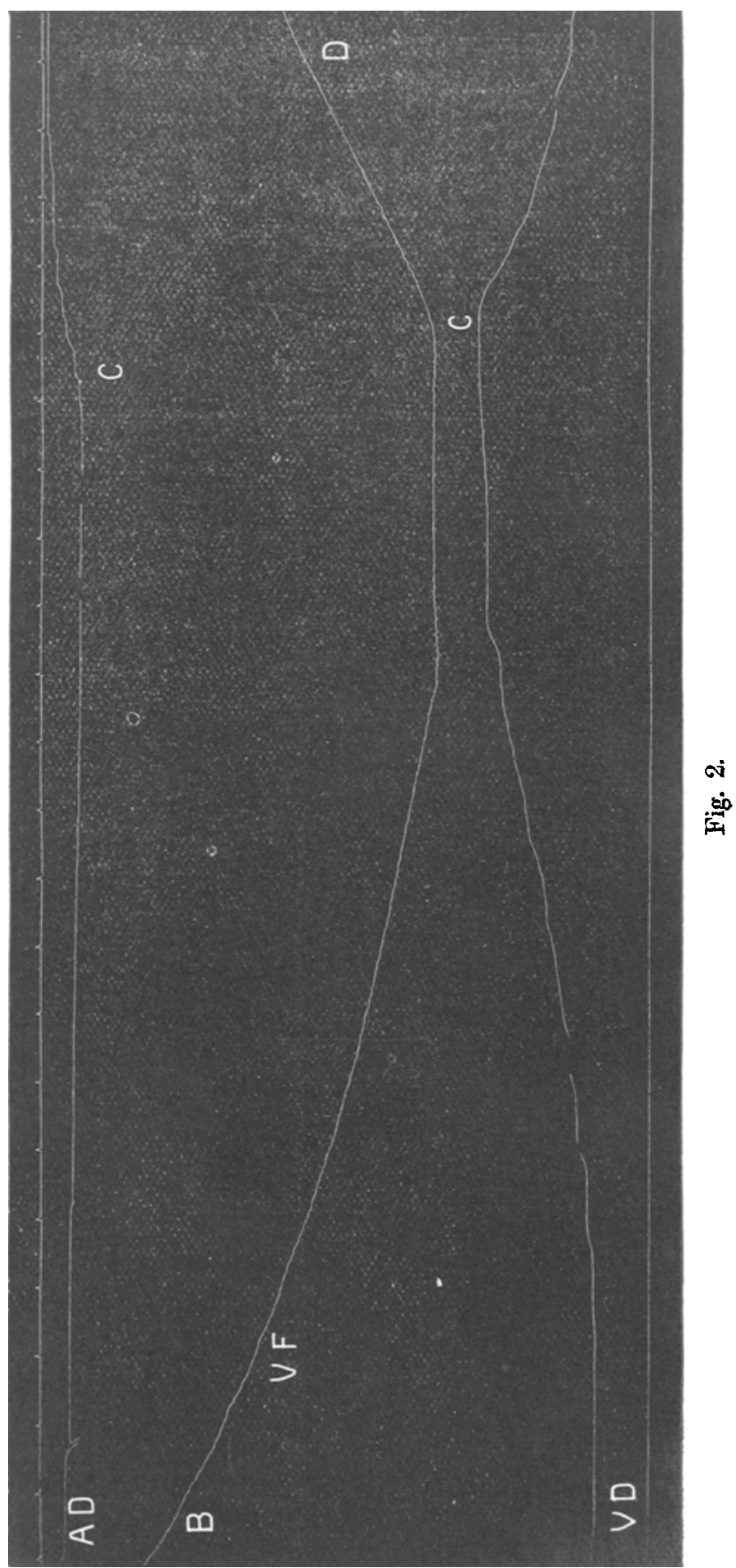


der Druck nicht wie vorher nach allen Richtungen hin verbreitet, sondern hauptsächlich gegen die untere Hohlvene gerichtet war.

\begin{tabular}{c|c|cc|c|c}
\hline \multirow{2}{*}{ Hund } & \multirow{2}{*}{ Gewicht } & \multicolumn{2}{|c|}{$\begin{array}{c}\text { Höchster Druck } \\
\text { mm Hg }\end{array}$} & \multicolumn{2}{|c}{$\begin{array}{c}\text { Strömungsvolum } \\
\text { Kubikzentim. pro Sekunde }\end{array}$} \\
\cline { 2 - 6 } & $\mathrm{kg}$ & $\begin{array}{c}\text { Banch- } \\
\text { höhle }\end{array}$ & $\begin{array}{c}\text { Vena } \\
\text { cruralis }\end{array}$ & Normal & $\begin{array}{c}\text { Abd. Druck } \\
\text { erhöht }\end{array}$ \\
\hline \multirow{2}{*}{1} & 10 & 25 & 19 & 0,71 & 0,35 \\
2 & 9 & 30 & 27 & 0,48 & 0,22 \\
3 & 15 & 45 & 41 & 0,73 & 0,09 \\
4 & 14 & 60 & 46 & 1,07 & 0,46 \\
\lrcorner & 14 & 70 & 64 & 0,89 & 0,06
\end{tabular}

Um festzustellen, ob die Ursache der venösen Stauung allein in der Bauchhöhle gelegen sei, wurden zwei Versuche an Hunden ausgeführt, deren Brustkasten weit eröffnet worden war. Auch unter diesen Umständen verursachte die Eiufübrung der Luft in die Bauchhöhle Hemmungen der Ströınung, welche den bei den normalen Tieren gefundenen um nichts nachstanden.

Weiterbin wurden mehrere Versuche an der Vena jugularis externà unter gleichen Bedingungen vorgenommen. Die Erhöhung des Druckes in der Bauchhöhle führte nie zu einer Stauung in diesem Blutgefässe. 